\title{
ON THE RELATION OF THE ORDER-PARAMETER AND TRANSITION TEMPERATURE IN FERROELECTRIC SOLID SOLUTIONS
}

\author{
W. WindsciI and H. BraEter \\ Universität Leipzig, Fakultät fïr Plıysik und Geowissenschaften \\ Limnéstr. 5, 04103 Leipzig, Germany \\ (Reccived April 19, 1994)
}

\begin{abstract}
Within the framework of the model of coupled anharmonic oscillators a ferroclectric solid solution is clescribed with only a few parameters. In high-temperature approximation a linear rclation between the square of the order parameter and the transition temperature is obtained. This is illustrated by an application to several modified lead titanate ceramics, the linear relation between transition temperature and tetragonal lattice deformation is verified. For tris-sarcosine calcium chloride (bromide) (TSCC/B) at very low temperatures the expected deviation from the classical behaviour is seen.
\end{abstract}

PACS numbers: $77.80 .13 \mathrm{~h}, 64.75 .+\mathrm{g}$

\section{Introduction}

It is cxpected that ferroclectrics with a large spontaneous polarization $P_{\mathbf{s}}$ show a high transition temperature $T_{c}$ since the competition between thermal fluctuations and internal ordering forces determines the state of the solid. The early statistical model for dipoles $\mu$ with density $N$ assuming feedback for the local field

$$
E_{\mathrm{loc}}=E_{\mathrm{ext}}+\beta P
$$

according to $\mathrm{P}$. Weiss (1907) leads to

$$
k T_{\mathrm{c}}=\beta N \mu^{2}=(\beta / N) P_{\mathrm{s}}(0)^{2},
$$

i.e. a proportionality between transition temperature $T_{c}$ and the square of the spontaneous polarization for $T=0$ [1].

A similar relation is slown in the book of Lines and Glass [2]. Using a mean-field IIamiltonian for the $l$-th $\mathrm{l}_{\mathrm{H}}$ it ccll with an anharmonic single-particle potential $V\left(\eta_{l}\right)$ and intercell interaction $\Phi_{\mathrm{ce}}$. They calculate the static displacement 
average $\left\langle\eta_{l}\right\rangle=\left\langle\eta_{l^{\prime}}\right\rangle=\langle\eta\rangle$ by means of a classical cnsemble average. Expansion of the exponentials to first order results in

$$
k T_{\mathrm{c}}=\phi_{0}\left\langle\eta(0)^{2}\right\rangle .
$$

Within this simple model the displacement is proportional to the spontaneous polarization at $T=0$

$$
k T_{\mathrm{c}}=K P_{\mathrm{s}}(0)^{2}
$$

where $K$ is independent of the local potential and primarily dependent only on the long-range intercell interaction. Lines and Glass suppose that $K$ should be universal within a class of structurally similar materials. 'They point to the paper of Abrahams et al. [3] who tried to find such a relation for perovskites.

In this paper we show using the model of coupled anlarmonic oscillators that within a class of displacive type ferroclectrics with equal symmetry of the critical mode a relation with a widcly universal proportionality constant holds. In high temperature approximation lincar relations betwen transition temperature and lattice parameters are obtained for ferroclectric solid solutions of perovskite type.

\section{Model calculations for ferroelectric solid solutions}

\subsection{Model}

Based on the existence of the soft optic mode Thomas proposed to apply the model of coupled anharmonic oscillators to ferroclectrics [1] (see also [5]). Aksenov et al. extcnded the model to include the effect of impuritics [6]. They used the following model IIamiltonian with an anharmonic single particle potential and harmonic cell interactions:

$$
\begin{aligned}
\widehat{I}= & \sum_{i, \alpha} \iota_{i \alpha}\left[\frac{p_{i \alpha}^{2}}{2 m}-\frac{1}{2} A_{\alpha} Q_{i \alpha}^{2}+\frac{1}{4} B_{\alpha} Q_{i \alpha}^{4}\right] \\
& +\frac{1}{4} \sum_{\alpha, \beta, i=j} \iota_{i \alpha} \iota_{j \beta} \phi_{i j}\left[Q_{i \alpha}-Q_{j \beta}\right]^{2} .
\end{aligned}
$$

$Q_{i, \alpha}$ are local normal coordinates. The projection operator $t_{i \alpha}$ sorts out the interaction parameters of the constituents $\alpha=1,2, \ldots$

We consider the case of only two components. 'Then the Ilamiltonian shall differ only by the parameters of the anharmonic single particle potential

$$
A_{2}=\gamma A_{1}, \quad B_{2}=\kappa B_{1} .
$$

For stability reasons $B_{1}, B_{2}>0$ holds. For ferroclectrics and quantum paraclectrics $A_{1}, A_{2}>0$ liolds, for a mixture of a ferroclectric (1) will a nonferroelectric (2) component $A_{2}<0$ holds and the fitting paraneter comes out to be $\gamma<0$. For a displacive type ferroclectric is $\sum \phi_{i j} / A_{1}=\phi_{0} / \lambda_{1} \gg 1$ (wcak anharmonicity).

To obtain the order paraneter in Eq. (2.1) we must minimize the free energy with respect to $\left\langle Q_{i \alpha}\right\rangle$. After configurational a veraging for the intercell interaction term in molecular ficld approximation an cxpression for the concentration dependence of the configurational averaged order parameter $Q_{0}$ is obtained. This 
expression includes the mean square fluctuations $\left\langle u_{\alpha}^{2}\right\rangle$ at a lattice site with configurational avcraged surroundings

$$
\left\langle u_{\alpha}^{2}\right\rangle=\frac{\hbar}{m} \int_{0}^{\omega_{\max }} \mathrm{d} \omega \rho_{\alpha}\left(\omega^{2}\right) \operatorname{clgh} \frac{h \omega}{2 k T} .
$$

The phonon densily $\rho_{\alpha}\left(\omega^{2}\right)$ is calculated by means of Green's function using self-consistent phonon approximation and virtual crystal approximation. The concentration dependent transition temperature $T_{\mathrm{c}}(x)$ is determined by the conditions for the order parameter $Q_{0}\left(T_{c}\right)=0$ and the soft mode frequency $\omega\left(q=0, T_{\mathrm{c}}\right)=0$. Then in comparison with the experiments the following equation is obtained:

$$
\frac{Q_{0}(x, T)^{2}}{Q_{0}\left(x^{\prime}, T^{\prime}\right)^{2}}=\frac{\frac{1-x(1-\gamma)}{1-x(1-\kappa)}+\left(3 B_{1} / A_{1}\right)\left\langle u\left(T^{\prime}\right)^{2}\right\rangle}{\frac{1-x^{\prime}(1-\gamma)}{1-x^{\prime}(1-\kappa)}+\left(3 B_{1} / A_{1}\right)\left\langle u\left(T^{\prime}\right)^{2}\right\rangle} .
$$

The presented model can very well clucidate the experimentally observed concentration dependence of the phase transition temperature and the order parameter in substitutionally mixed ferroclectric and quantum paraclectric crystals $\mathrm{TSC}(\mathrm{Cl}, \mathrm{Br})[7], \mathrm{K}(\mathrm{Na}, \mathrm{Nb}) \mathrm{O}_{3}[8],(\mathrm{Pl}, \mathrm{Sr})^{\prime} \mathrm{TiO}_{33}[9],(\mathrm{Ba}, \mathrm{Sr})^{\circ} \mathrm{TiO}_{3}[10]$ as well as the mixed ferroelectric ceramics $(\mathrm{Pb}, \mathrm{La})^{\prime} \mathrm{TiO}_{3}[11]$. 'The numerical calculations are in good agreement with the experimental findings.

The condition for the application of this model to mixed ferroclectrics scems at first sight to be given by the requirement that the pure components are isomorphous, i.e. they exhibit the sane space group. But the main requirement is that by substitution of one component by the other the symmetry of the critical mode is not changed [6].

\subsection{ITigh lemperalure approximation.}

For the investigation of ferroclectric ceramics it is useful to pass to the high-temperature approximation (II'I'A) of Eq. (2.1). In expression of Eq. (2.3) for the mean square fluctuations $\operatorname{ctgh} x=1 / x+x / 3+\ldots$ is expanded. The fluctuations depend on the upper limit $\omega_{\max }$ of the dispersion of the soft optic mode. Numerical estimations show that for perovskites in the whole frequency spectrum of the soft mode one can approximate $\operatorname{ctg} \operatorname{li} x \approx 1 / x$. Then for mixed ceramics with concentration of the admixture $x$ the following is obtained:

$$
\frac{T_{\mathrm{c}}(x)}{T_{\mathrm{c}}(0)}=\frac{1-x(1-\gamma)}{1-x(1-\kappa)} .
$$

Substitution of this expression into Eq. (2.4) results

$$
\frac{Q_{0}(x, T)^{2}}{Q_{0}\left(x^{\prime}, T^{\prime}\right)^{2}}=\frac{T_{\mathrm{c}}(x)-T}{T_{\mathrm{c}}\left(x^{\prime}\right)-T^{\prime}} .
$$

The whole solid solution is described by the single particle potential parameters $\gamma$ and $k$ and one pair of experimental data $\left[Q_{0}\left(x^{\prime}, T^{\prime}\right), T_{c}\left(x^{\prime}\right)\right]$ as refcrence, where $\left[x^{\prime}, T^{\prime}\right]$ are arbitrarily chosen cxperinental conditions. 


\subsection{Discussion}

One can rewritc Eq. (2.6) as

$Q_{0}(x, T)^{2}=\frac{Q_{0}\left(x^{\prime}, T^{\prime}\right)^{2}}{T_{\mathrm{c}}\left(x^{\prime}\right)-T^{\prime}}\left(T_{\mathrm{c}}(x)-T\right)$.

This is valid also for $T=0$

$Q_{0}(x, 0)^{2}=\frac{Q_{0}\left(x^{\prime}, T^{\prime \prime}\right)^{2}}{T_{\mathrm{c}}\left(x^{\prime}\right)-T^{\prime \prime}} T_{\mathrm{c}}(x)$.

This relation is equivalent to the relations obtained using the Weiss theory and by Lines and Glass. But we have to keep in mind that this relation is exact only in case when the quantum fluctuations are negligible.

The proportionality constant

$$
A=\frac{Q_{0}\left(x^{\prime}, T^{\prime}\right)^{2}}{T_{c}\left(x^{\prime}\right)-T^{\prime}}
$$

may be estimated at any temperature for any composition within the class of considered ferroclectrics.

One can also compare two isomorphous ferroelectrics with the same symmetry of the critical mode. Onc can consider them as the end points of a solution, i.e. $x=0$ and $x=1$. Then it is obtaincel

$$
\frac{Q_{0}(1, T=0)^{2}}{Q_{0}(0, T=0)^{2}}=\frac{T_{c}(1)}{T_{c}(0)}=\frac{\gamma}{i i} \text {. }
$$

The essential ferroclectric propertics are related by their single particle potentials. In this manner it is possible to compare the ferroclectric properties of $\mathrm{PbTiO}_{3}$ and $\mathrm{BaTiO}_{3}$ in their tetragonal phases. Both of them show the first order transition $P 4 \mathrm{~mm} \Leftrightarrow \mathrm{Om} 3 \mathrm{~m}$ and their soft modes show besides slightly different behaviour the same symmetry. The published data $[2,12,13]$ result in $T_{\mathrm{c}}(\mathrm{Pb}) / T_{\mathrm{c}}(\mathrm{Ba})=$ $1.93 \pm 0.02$. Earlier calculations [11] resulted in $\gamma / n=2.3 \pm 0.4$. 'This is a really good agrcement. The proportionality constants $A(\mathrm{Ba})$ and $A(\mathrm{~Pb})$ calculated according to Eq. (2.9) should be cqual. From a consideration of the spontancous polarizations at room temperature $A(B a) / A(P \mathrm{P}))=0.8$ is obtained which is, in spite of the usual error in the values for the spontancous polarization, also in grood agreement with our model.

Equation (2.7) shows its affinity to the Landau theory. For $x=x^{\prime}$ and $T^{\prime}=0$ one obtains for $Q_{0}(x, T)$ the wcll-known relation for continuous phase transitions. But the reverse conclusion is not possible. With two Landau formula for different concentrations it is not possible to derive Eq. (2.7), since the systems are not coupled. In the model the two components are coupled by Eqs. (2.2) with $\gamma$ and $r$.

The self-consistent phonon approximation always provides first order phase transitions [5]. Only in the displacive limit a continuous phase transition follows. But it is shown below that the behaviour of mixed ferroclectrics with continuous as well as discontinuous phase transitions may be described sufficiently exact. 


\section{Perovskite ceramics}

Many $\mathrm{ABO}_{3}$ compounds with perovskite structure exhibit ferroelectric properties. From the point of view of both plyysical properties and device applications the research on $\mathrm{BaTiO}_{3}$ and $\mathrm{l}^{\prime} \mathrm{b}^{\prime} \mathrm{TiO}_{3}$ is especially extensive. The electrical conductivity, the piezoclectric and other propertics of ccramics based on these materials can be matched to spccial application requirements by incorporation of foreign ions into the perovskite lattice. Piezoclectric devices for wide applications are obtained by modification of $\mathrm{Pb}^{\prime} \mathrm{TiO}_{3}$ by addlition of oxides of lanthanum, calcium or zirconium. The ferroclectric properties of such ceramics can be described with our model.

\subsection{Calcium modified lead lilanale ceramics}

For sintered ceramics with composition $\mathrm{Pb}_{1-x} \mathrm{Ca}_{x}\left(\mathrm{Co}_{0.5} \mathrm{~W}_{0.5}\right)_{0.05} \mathrm{Ti}_{0.95} \mathrm{O}_{3}$ $+1 \% \mathrm{MnO}_{2}$ the phase transition temperature and at room tempcrature the lattice parameters were measured as a function of the calcium concentration in the range $x=0.01$ to 0.45 . In this range a clearly tetragonal structure with no superstructure was observed [11]. The lattice parameters are related to the spontaneous polarization $P_{\mathrm{s}}(x, T)$ by

$$
\frac{c}{a}-1=\left(Q_{\|}-Q_{\perp}\right) P_{\mathrm{s}}^{2}\left(1-Q_{\perp} P_{\mathrm{s}}^{2}\right) \text {. }
$$

$Q_{\|}$and $Q_{\perp}$ are the longitudinal and transversal clectrostrictive constants. As the order parameter we use

$$
Q_{0}(x)=\left[\frac{c(x)}{a(x)}-1\right]^{1 / 2}
$$

normalized to the electrostrictive constants of $\mathrm{Pb}^{\prime} \mathrm{TiO}_{33}$. Since no experimental data on the concentration and temperature dependence of the electrostriction are available, the room temperature values of $Q_{\|}$and $Q_{\perp}$ given in Ref. [12] were used. Neglecting of the correction term $Q_{\perp} P_{\mathrm{s}}^{2}$ lcads to an error of less than $1.5 \%$.

Figure 1 shows the experimentally obtained values of $c / a-1$ and $T_{\mathrm{c}}$ as a function of calcium concentration. They were fitted to the relations

$$
T_{\mathrm{c}}(x)=T_{\mathrm{c}}(0) \frac{1-x(1-\gamma)}{1-x(1-\mu)}
$$

and

$$
Q_{0}(x)=Q_{0}(0) \frac{T_{\mathrm{c}}(x)}{T_{\mathrm{c}}(0)} \frac{1}{x_{\mathrm{c}}} \frac{x_{\mathrm{c}}-1}{1-x(1-\gamma)},
$$

which were derived from Eqs. (2.4) in JITA.

The following parameters wcre obtained by best fits:

$$
\gamma=-0.58, \kappa=0.26, x_{c}=0.49 \text {. }
$$

$x_{\mathrm{c}}\left(T_{\mathrm{B}}\right)$ is a temperature dependent critical concentration, for $x \geq x_{\mathrm{c}}$ at the observation temperature $T_{\mathrm{B}}$ the sample is nonpolar. The negative sign of $\gamma$ confirms that $\mathrm{Ca}$ is a hard defect, i.c. the unit cell with incorporated $\mathrm{Ca}$ does not possess a double minimum potential. 


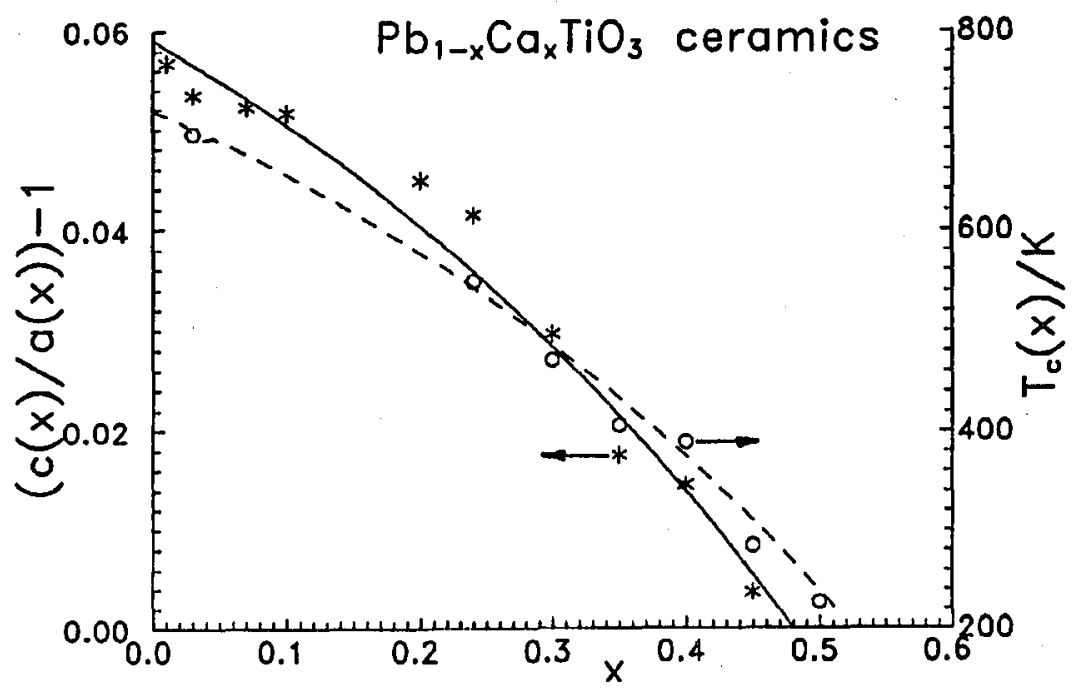

Fig. 1. Ferroelcctric transition temperature $T_{\mathrm{c}}(x)(*)$ and tetragonality $c(x) / a(x)-1$ (o) (at room temperature) of calcium modified $\mathrm{PbTiO}_{3}$ ceramics as a function of calcium concentration $x$ [14]. The solid and the dashed line are calculated with the fit parameters given in the text.

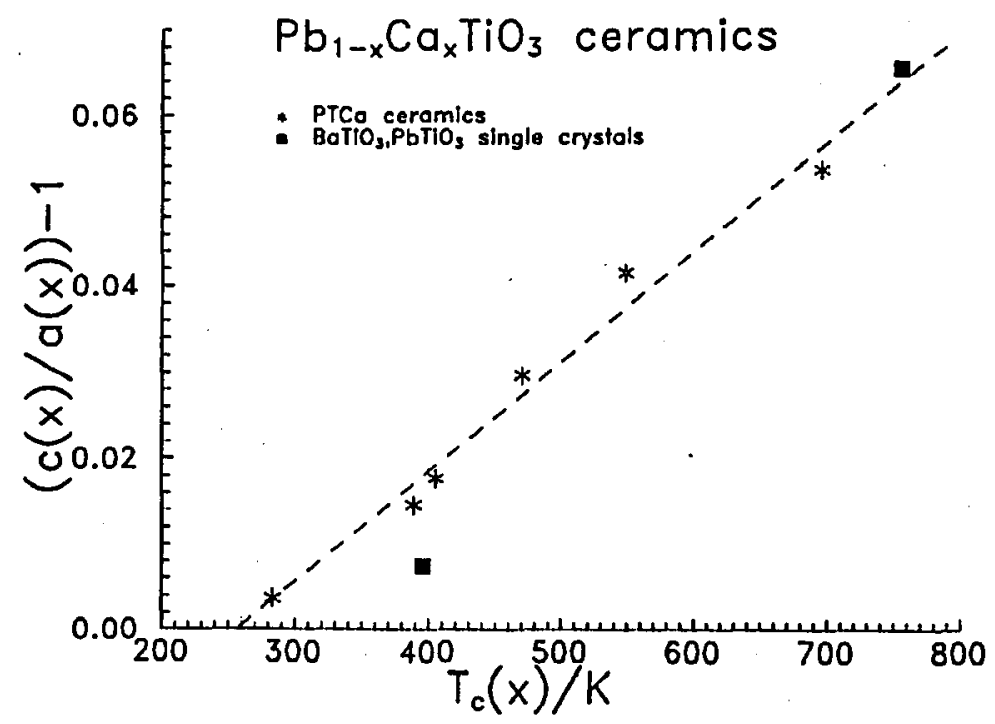

Fig. 2. Transition temperature $T_{c}(x)$ vs. tetragonality $c(x) / a(x)-1$ (at room temperature) of calcium modified $\mathrm{PbTiO}_{3}$ ceramics [14]. The dashed line is obtained by linear regression. For comparison the values for $\mathrm{PbTiO}_{3}$ and $\mathrm{BaTiO}_{3}$ single crystals $[12,15]$ are added. 
The expected linear relation between the square of the order parameter $Q_{0}(x, T)^{2}$ and the transition tempcrature $T_{\mathrm{c}}(x)$ shows Fig. 2. The gradient

$$
A=\frac{Q_{0}\left(x^{\prime}, T^{\prime}\right)^{2}}{T_{\mathrm{c}}\left(x^{\prime}\right)-T^{\prime}}=1.28 \times 10^{-4} \mathrm{~K}^{-1}
$$

was obtained by a linear regression. Its value is universal for the system $\mathrm{XTiO}_{3}$. This is seen by the included values for $\mathrm{BaTiO}_{3}$ and $\mathrm{PbTiO}_{3}$ single crystals $[12,15]$. The gradient $A$ for a line connecting these values is nearly the same as that obtained from averaging on the ccramics values.

\subsection{Lanthanum modified lead litanate ceramics}

The introduction of $\mathrm{La}^{3+}$ into the $\mathrm{Pb}^{2+}$ sublattice creates $\mathrm{Pb}^{2+}$ vacancics $\mathrm{V}\left(\mathrm{Pb}^{2+}\right)$ [16]. Therefore the ceramics $\mathrm{Pb}_{1-x} \mathrm{La}_{2 / 3 x} \mathrm{TiO}_{3}$ can be considered within the framework of the proposed model of Eq. (1) as a threc-component system [11]:

- $\mathrm{PbTiO}_{3}$ as a ferroclectric,

- $\mathrm{LaTiO}_{3}$ as a "hard defect",

- $\mathrm{V}\left(\mathrm{Pb}^{2+}\right) \mathrm{TiO}_{3}$ with no single particle potential.

Then this system is described as earlicr by the parameters $\gamma$ and $\kappa$.

The experimental values of $T_{\mathrm{c}}(x)$ and $c(x) / a(x)$ obtained by Fedulov et al. [17] were fitted. We obtained $\gamma=-0.41, i=1, x_{\mathrm{c}}=0.42$.

The linear relation between $Q_{0}(x)^{2}$ and $T_{\mathrm{c}}(x)$ is well fulfilled as is seen in Fig. 3. The gradient $A=1.37 \times 10^{-4} \mathrm{~K}^{-1}$ is near to this of the Ca modified ceramics as is expected.

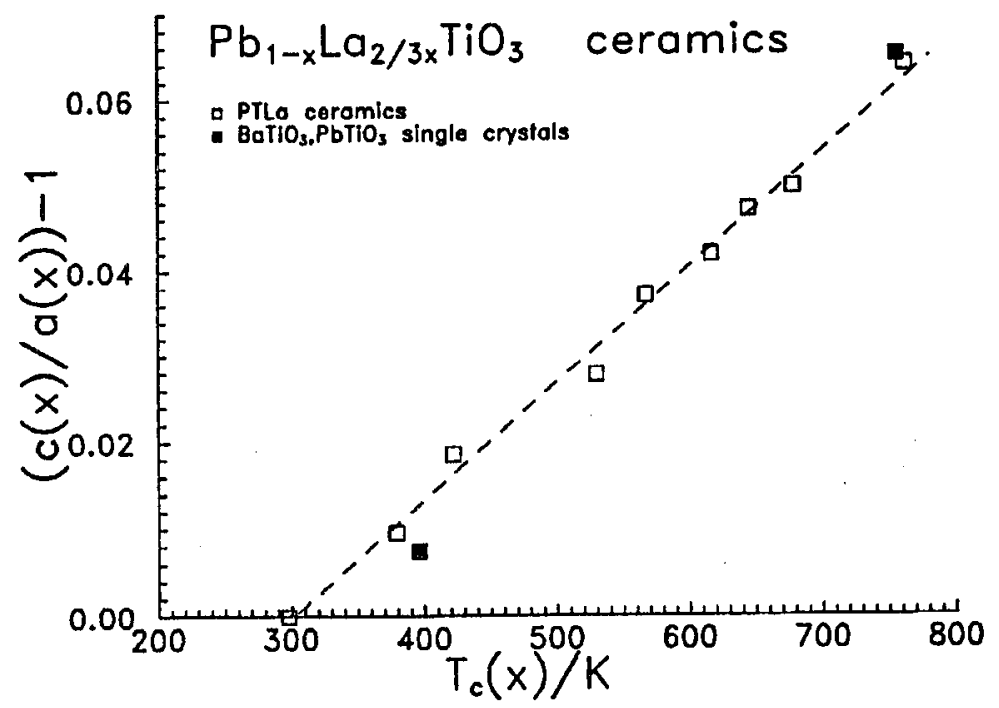

Fig. 3. Transition tempcrature $T_{c}(x)$ vs. tetragonality $c(x) / a(x)-1$ (at room temperature) of lanthanum modified $\mathrm{PbTiO}_{3}$ ceramics [19]. The dashed line is obtained by lincar regression. For comparison the valucs for $\mathrm{PbTiO}_{3}$ and $\mathrm{BaTiO}_{3}$ single crystals are added. 
In comparison we also treated the results obtained by Sasaki and Matsuo [18]. Their values show slightly nonlinear behaviour. For the gradient is obtained $A=1.35 \times 10^{-4} \mathrm{~K}^{-1}$. For comparision experiments are included in Fig. 6 which summarizes the results of the investigations on several modified $\mathrm{PbTiO}_{3}$ ceramics.

\subsection{Mixed lead lilanale and strontium zirconate}

It is interesting to investigate $\mathrm{PbTiO}_{3}$ ceramics by substitution into two sublattices. Fedulov and Venevtsev [19] measured the system $(\mathrm{PbTi})_{1-x}(\mathrm{SrZr})_{x} \mathrm{O}_{3}$ for $x=0$ to 0.35 . The relation between $Q_{0}(x, T)$ and $T_{\mathrm{c}}(x)$ shows the same trend as before but it is slightly nonlinear (see Fig. 6).

\subsection{Bollh components are ferroelectric}

Until now we discussed the cases of paraclectric dilution of $\mathrm{PbTiO}_{3}$, but an admixture of a ferroelectric component is also well described. $\mathrm{PbZn}_{1 / 3} \mathrm{Nb}_{2 / 3} \mathrm{O}_{3}$ is ferroelectric below $413 \mathrm{~K}$. In the ferroelectric phase it is rhombohedral with $a=4.061 \AA$ and $\alpha=89^{\circ} 55^{\prime}$, in the paraclectric phase it is cubic. The admixture of $\mathrm{PbZn}_{1 / 3} \mathrm{Nb}_{2 / 3} \mathrm{O}_{3}$ to $\mathrm{PbTiO}_{3}$ results in a monotonous decrease in the transition temperature $T_{\mathrm{c}}(x)$ and the $c / a$ ratio with increasing amount of $\mathrm{PbZn}_{1 / 3} \mathrm{Nb}_{2 / 3} \mathrm{O}_{3}$. Up to $x=0.905$ the mixed system is tetragonal, above $x=0.91$ it is rhombohedral [20].

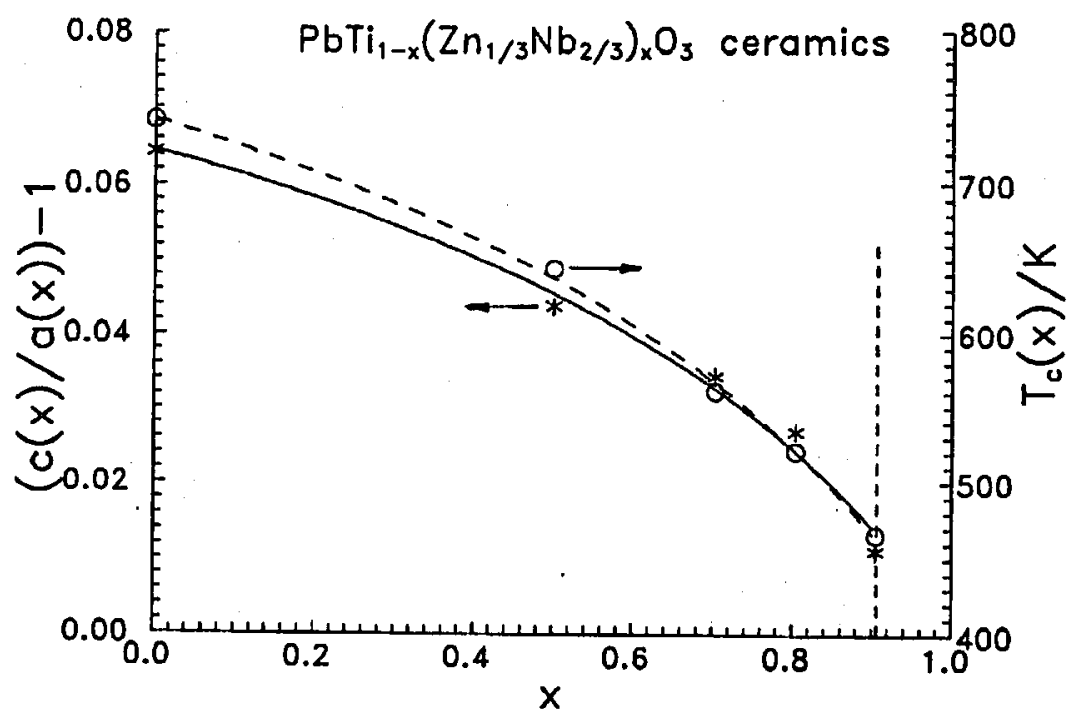

Fig. 4. $T_{c}(x)(0)$ and $c(x) / a(x)-1(*)$ vs. $x$ for PTZnNb ceramics [20]. The solid and the dashed line are calculated with the fitting parameters given in the text.

The fit of the concentration dependence of the transition temperature $T_{\mathrm{c}}(x)$ using Eq. (3.3) results in $\gamma=0.23, \kappa=0.34$. These parameters describe also 


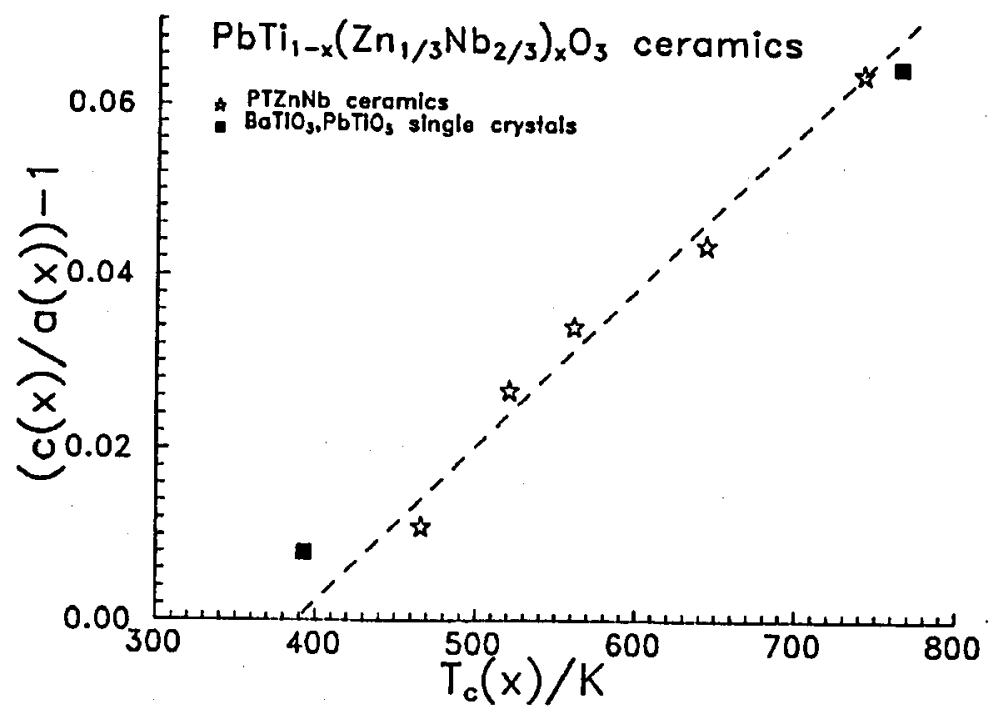

Fig. 5. $c(x) / a(x)-1$ vs. $T_{c}(x)$ for $\mathrm{PTZ} n \mathrm{nb}$ ceramics [20]. The dashed line is obtained by linear regression. For comparison the values for $\mathrm{PbTiO}_{3}$ and $\mathrm{BaTiO}_{3}$ single crystals are added.

well the concentration dependence of the order parameter using Eq. (2.4) in high-temperature approximation (see Fig. 4). The positive sign of $\gamma$ confirms that the admixture is also ferroelectric, the markedly deviation of $\kappa$ from 1 points to a considerable nonlinearity of $T_{\mathrm{c}}(x)$ vs. $x$. For $x=0$ to 0.90 the expected linear relation between $c / a-1$ and $T_{c}(x)$ is obtained. The gradient is $A=1.81 \times 10^{-4} \mathrm{~K}^{-1}$, which is not far from the earlier obtained values for paraelectric dilution in $\mathrm{PbTiO}_{3}$ (see Fig. 5).

\subsection{Discussion}

For the description of ferroclectric ceramics within the model of coupled anharmonic oscillators only a few easily accessible parameters are necessary. If the constituents are isomorphous and their ionic radii differ not more than about $15 \%$ one can expect the existence of the solution in the whole concentration range $x=0$ to 1. The system $\mathrm{Pb}_{1-x} \mathrm{Ba}_{x}{ }^{\prime} \mathrm{TiO}_{3}$ is such a candidate. $\mathrm{CaTiO}_{3}, \mathrm{LaTiO}_{3}, \mathrm{SrZrO}_{3}$, and $\mathrm{PbZn}_{1 / 3} \mathrm{Nb}_{2 / 3} \mathrm{O}_{3}$ are not isomorphous to $\mathrm{PbTiO}_{3}$, therefore the symmetry of $\mathrm{PbTiO}_{3}(\mathrm{P} 4 \mathrm{~mm})$ is conserved only in a limited concentration range, experimentally was obtained $x_{l}(\mathrm{Ca}) \approx 0.45, x_{l}(\mathrm{La}) \approx 0.35, x_{l}(\mathrm{Sr}) \approx 0.35, x_{l}(\mathrm{ZnNb})=$ 0.905 .

Obviously the admixture of foreign ions into perovskite ceramics in a rather wide range does not change the symmetry of the soft optic mode and the most important condition for the application of the model of coupled anharmonic oscillators is fulfilled. This was confirmed by spectroscopic investigations on lanthanum modified lead titanate ceramics. Fourier transform infrared (FTIR) spectra revealed in addition to $\mathrm{PbTiO}_{3}$ the existence of $\mathrm{LaTiO}_{3}$ and several species of 
$(\mathrm{Pb}, \mathrm{La}) \mathrm{TiO}_{3}$ [21]. Raman spectra showed a continuous shift of the vibration bands with increasing La content. Clearly single mode behaviour is exhibited [22]. This confirms the application of the virtual crystal approximation as has been done by the calculation of the basic relation of Eq. (2.4), which provides by means of Eq. (3.2) the linear dependence of the tetragonality on the transition temperature of several modified ceramics as shown in Fig. 6.

$A$ reason for the scattering of the expcrimental values is the smearing out of the ferroelectric transition by admixture. Then it is not possible to determine exactly the transition temperature by means of dielectric measurements [23].

Another point is the change of the character of the ferroelectric transition by admixture. The transitions $P 4 m m \Leftrightarrow O m 3 m$ of $\mathrm{PbTiO}_{3}$ and $\mathrm{BaTiO}_{3}$ are of the first order. The temperature dependence of $c / a$ of $\mathrm{Pb}_{1-x} \mathrm{Ca}_{x} \mathrm{TiO}_{3}$ ceramics with $x=0.24$ reveals that it is very close to the tricritical behaviour [14]. Besides smearing out of the transition it also becomes continuous by admixture of $\mathrm{Ca}$ (cf. Fig. 6).

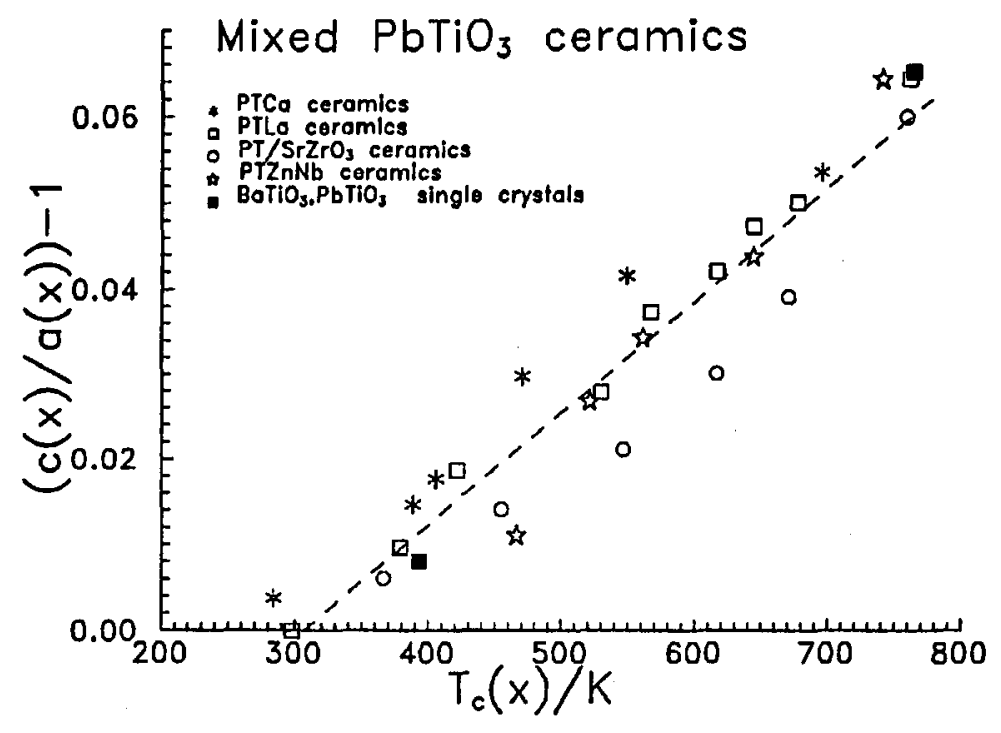

Fig. 6. Tetragonality $c(x) / a(x)-1$ (at room temperature) vs. transition temperature $T_{\mathrm{c}}(x)$ of several modified $\mathrm{PbTiO}_{3}$ ceramics. For comparison the values for $\mathrm{PbTiO}_{3}$ and $\mathrm{BaTiO}_{3}$ single crystals are added. The dashed line is obtained by a linear regression of the experimental values for all ceramic systems inclucled in the diagram.

It was also found that experimental values of the spontaneous polarization are much less reliable than the values for the lattice constants. Drawing $P_{\mathrm{s}}(x)^{2}$ vs. $T_{\mathrm{c}}(x)$ docs not give the clear picture as discussed above.

\section{Influchce of quantum effects}

A solid solution consisting of a ferroelectric and a quantum paraelectric usually reaches for a critical concentration $x_{\mathrm{c}}$ the quantum limit, $T_{\mathrm{c}}\left(x_{\mathrm{c}}\right)=0$. Well 
known examples among the perovskite (quasi) ferroelectrics are $\mathrm{KTa}_{1-x} \mathrm{Nb}_{x} \mathrm{O}_{3}$ and $\mathrm{K}_{1-x} \mathrm{Na}_{x} \mathrm{TaO}_{3}[24,25]$. The first quantum paraelectric molecular crystal was $\mathrm{TSCC}_{1-x} \mathrm{~B}_{x}$ (tris-sarcosine calcium chloride (bromide)) [7].

For obscrvation temperatures $T_{B}$ below about $40 \mathrm{~K}$ due to the influence of quantum fluctuations deviations from the high temperature behaviour are expected. An evaluation of the influence of these effects on the isotherms in the phase diagram $(T, Q(x, T))$ is possible by the modification of Eq. (2.4). One can write

$$
\begin{aligned}
& \left\langle u\left(T_{\mathrm{c}}(x)\right)^{2}\right\rangle=\left[\frac{T_{\mathrm{c}}(x)}{T_{\mathrm{c}}(0)}+\delta\left(T_{\mathrm{c}}(x)\right)\right] \frac{A_{1}}{B_{1}}, \\
& \left\langle u\left(T_{\mathrm{B}}\right)^{2}\right\rangle=\left[\frac{T_{\mathrm{B}}}{T_{\mathrm{c}}(x)}+\delta\left(T_{\mathrm{B}}\right)\right] \frac{A_{1}}{B_{1}},
\end{aligned}
$$

where the $\delta(T)$ describe the contribution of the quantum fluctuations at temperature $T$. For $T_{\mathrm{c}}(0) \gg T_{\mathrm{B}}$ it follows that

$$
\begin{aligned}
\frac{Q_{0}\left(x, T_{\mathrm{B}}\right)^{2}}{Q_{0}\left(0, T_{\mathrm{B}}\right)^{2}}=\frac{T_{\mathrm{C}}(0)\left(1+\delta\left(T_{13}\right)\right)-T_{\mathrm{B}}}{\left(T_{\mathrm{C}}(0)-T_{\mathrm{B}}\right)^{2}} & \\
\times & \times\left\{T_{\mathrm{c}}(x)-T_{\mathrm{B}}+T_{\mathrm{c}}(0)\left[\delta\left(T_{\mathrm{c}}(x)\right)-\delta\left(T_{\mathrm{B}}\right)\right]\right\} .
\end{aligned}
$$

The relation between $Q_{0}\left(x, T_{\mathrm{B}}\right)^{2}$ and $T_{\mathrm{c}}(x)$ remains linear but the gradient as well as the intercept are changed.

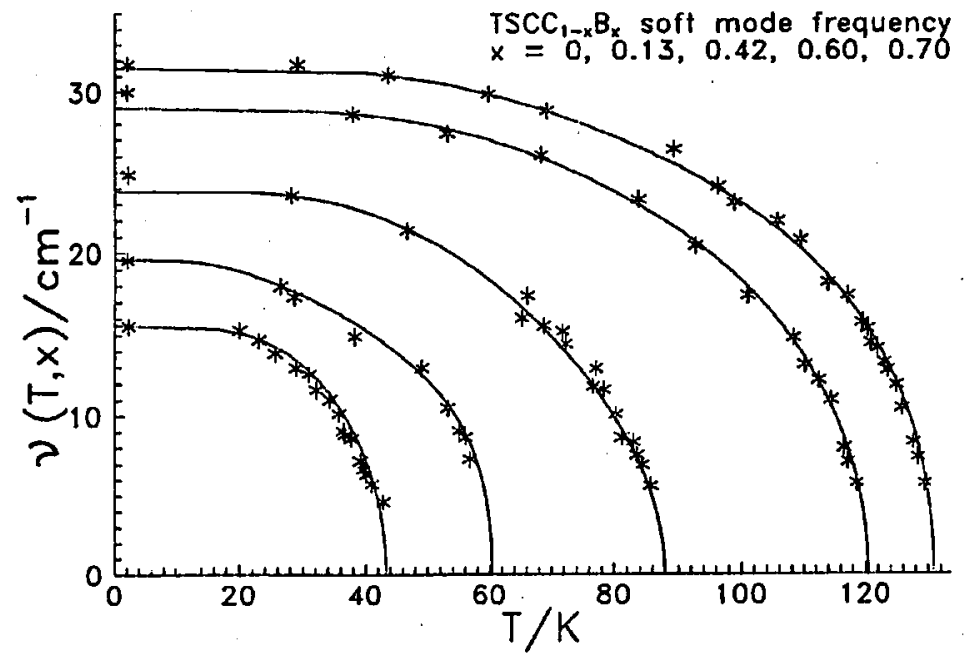

Fig. 7. Temperature dependence of the soft mode frequency of $\mathrm{TSCC}_{1-x} \mathrm{~B}_{x}$ obtained by Raman spectroscopy for $x=0 ; 0.13 ; 0.42 ; 0.60$ and 0.70 [26]. The solid lines are obtained by a fit to an equation derived from the effective field method [1].

Figure 7 shows the results of a measurement of the soft mode frequency of $\mathrm{TSCC}_{1-x} \mathrm{~B}_{x}$ using Raman spectroscopy [26]. It is clearly seen that $d \nu /\left.\mathrm{d} t\right|_{T=0}=0$. This is expected from a consideration of the influence of quantum fluctuations [27]. Therefore the experimental values were fitted using equations derived by the effective field method [1] and not by Landau theory. 


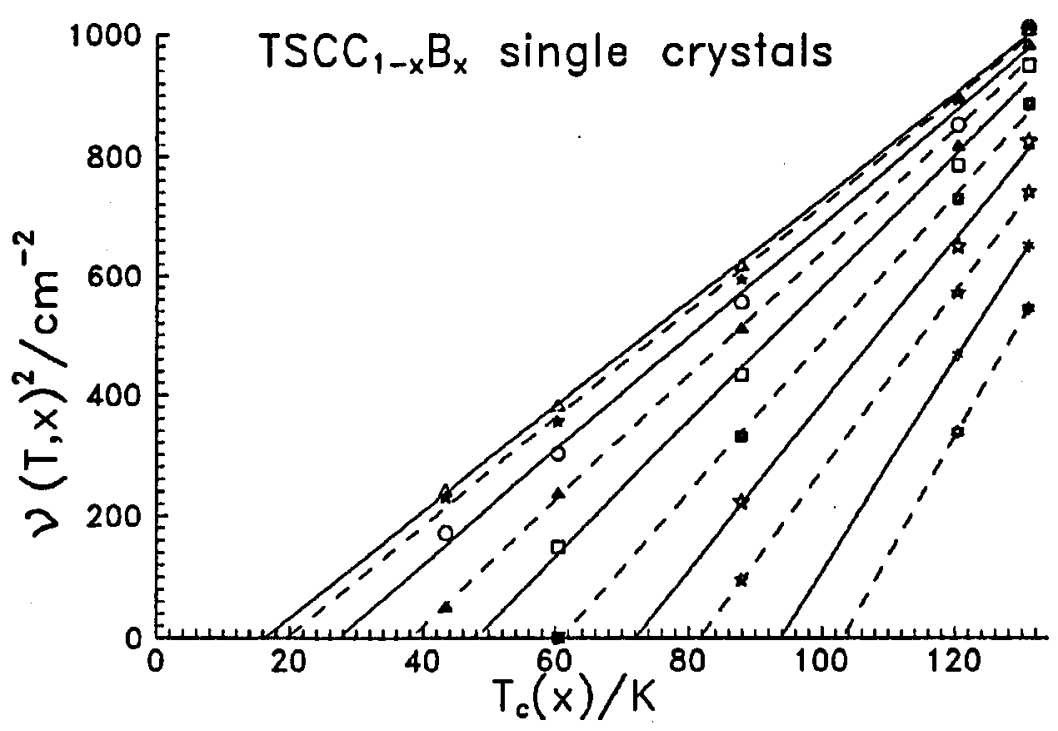

Fig. 8. Relation between the square of the soft mode frequency of $\operatorname{TSCC}_{1-x} \mathrm{~B}_{x}$ and the concentration dependent transition temperature $T_{c}(x)$ for isotherms at $T_{\mathrm{B}}=2 \mathrm{~K}$; $20 \mathrm{~K} ; 30 \mathrm{~K} ; 40 \mathrm{~K}$ to $100 \mathrm{~K}$. The solid and dashed lines are obtained by linear regression.

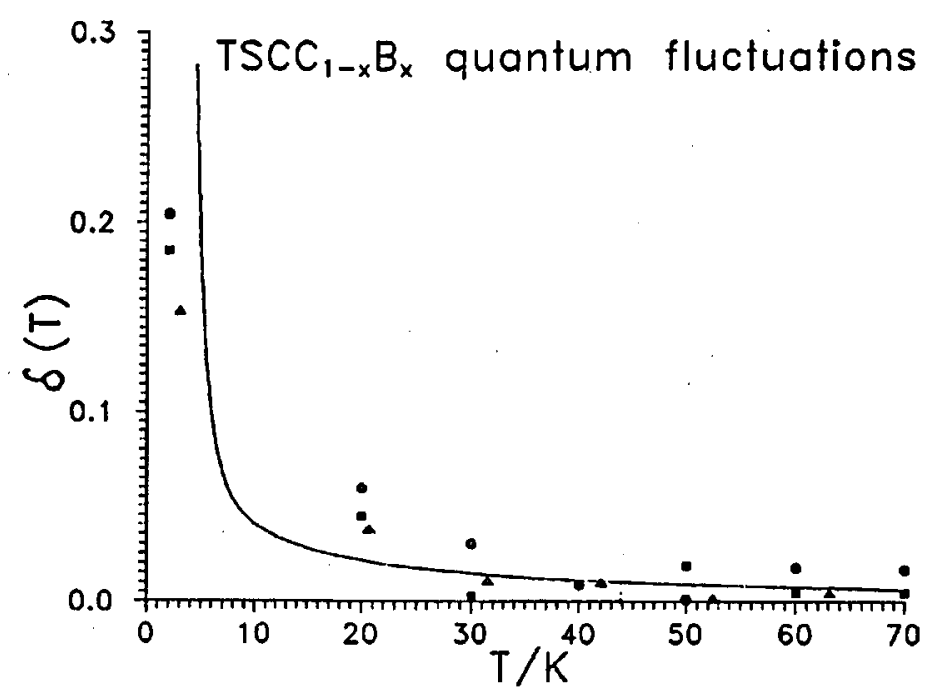

Fig. 9. Deviation [rom classical bchaviour due to quantum flucluations for the soft mode of $\operatorname{TSCC}_{1-x} B_{x}$. The line is calculated for $h \omega / k T_{c}=0.4$.

As expected, the isotherms in Fig. 8 are not parallel. Detailed numerical considerations reveal that this is due to the deviation from $Q_{0}(x, T)^{2} \approx$ $T_{\mathrm{c}}(x)-T$, which follows from Eq. (2.4). Only at very low temperatures the influence of quantum effects is superimposed and is therefore hardly to detect. But the 
effect on the isotherm for $T_{13}=2 \mathrm{~K}$ is clearly seen. $\nu\left(x, T_{\mathrm{B}}\right)^{2}$ vs. $T_{\mathrm{c}}(x)$ is for the isotherm $T_{\mathrm{B}}=2 \mathrm{~K}$ much steeper than for the next isotherm at $T_{\mathrm{B}}=20 \mathrm{~K}$.

Figure 9 shows the values of $\delta\left(T_{13}\right)$ estimated by several numerical methods. Obviously, the crror is rather large but the tendency is seen. More experiments at very low temperature would be useful. An cxpansion of the integral of the mean square fluctuations results in

$$
\frac{\hbar \omega_{\max }}{k T_{\mathrm{c}}(0)} \approx\left[\frac{36 \delta\left(T_{\mathrm{B}}\right)}{T_{\mathrm{c}}(0) / T_{\mathrm{i3}}}\right]^{1 / 2}
$$

The solid line in Fig. 9 is calculated by using $\hbar \omega_{\max } / k T_{\mathrm{c}}(0)=0.4$. Earlier measurements [28] led to $\hbar \omega_{\max } \approx k T_{\mathrm{c}}$.

\section{Acknowledgments}

One of us (W.W.) is indebted to the Spanish Ministerio de Education y Ciencia for supporting a three-month stay at the Universidad Autonoma de Madrid where this research began. Ile benefited also from many discussions after a lecture at the XX International Scliool on Ferroclectrics Physics, Karpacz (Poland), 1993.

\section{Refierences}

[1] J.A. Gonzalo, Effective Ficld Approach to Phase Transilions and Some Applications to Ferroelectrics, World Scientific Publ., Singapore 1991.

[2] M.E. Lines, A.M. Glass, Principles and Applicalions of Ferroclectrics, Clarendon Press, Oxford 1977.

[3] S.C. Abrahıans, S.K. Kürtz, P.B. Jamicson, Phys. Rev. 172, 551 (1968).

[4] II. Thomas, in: Structural Phase Transilions and Soft Modes, Eds. E.S. Samuelsen, E. Andersen, J. Feder, Universitetsforlaget, Oslo 1971, p. 15.

[5] A.D. Bruce, Adv. Phys. 20, 111 (1980).

[6] V.L. Aksenov, II. Bracter, N.M. Plakida, Sov. Phys. Solid Stale 20, 846 (1975).

[7] W. Windscl, II. Bracter, Ann. Phys. 43, 621 (1985).

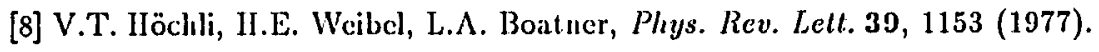

[9] II. Bracter, W. Windsch, V.L. Akscnov, Ferroclectrics Lell. 3, 250 (1985).

[10] E. ITegenbarth, KTB Martin-Luther-Universität IIalle-Wittenberg, WB 49 (O9) 52 (1981).

[11] H. Braeter, W. Windsch, KTB Martin-Luther-Universität IIalle-Wittenberg, WB 190/37 (O33) 33 (1987).

[12] M.J. IIaun, E. Furman, S.J. Jang, II.A. McKinstry, L.E. Cross, J. Appl. Phys. 62, 3331 (1987).

[13] S.A. Sonin, B.A. Strukow, Einführung in die Ferrocleklrizilial, Akademie-Verlag, Berlin 1974.

[14] W. Windsch, II. Bracter, L. Pardo, B. Jincncz, J. Mendiola, J.A. Gonzalo, to be published.

[15] F. Jona, G. Shiranc, Ferroclcctric Crystals, Pergamon Press, Oxford 1962.

[16] D. Ilenuings, K.II. IIärdıl, Phys. Slatus Solidi A 3, 165 (1970). 
[17] S.A. Fedulov, I.B. Feldman, E.N. Roditchev, Izv. Ak. Nauk, Ser. Fiz. 29, 2050 (1965).

[18] H. Sasaki, Y. Matsuo, Ceramic Bull. 51, 164 (1972).

[19] S.A. Fedulov, Ju.N. Venevtsev, Fiz. Tverd. Tela 3, 3371 (1961).

[20] S. Nomura, T. Takahiashi, Y. Yokomizo, J. Phys. Soc. Jpn. 27, 262 (1969).

[21] R. Salzer, J. Dressler, M.K. Gergs, D. Michel, II. Schlemmbach, W. Windsch, P. Reich, J. Mol. Struct. 219, 17 (1990).

[22] W. Windsch, M.K. Gergs, D. Michel, II. Schlemmbach, R. Salzer, P. Reich, Ferroelectrics 109, 119 (1990).

[23] G. Lifante, J.A. Gonzalo, W. Windsch, Ferroclectrics 146, 107 (1993).

[24] V.T. Iöchli, L.A. Boatncr, Phys. Rev, B 20, 266 (1979).

[25] V.T. IÏchli, II.E. Wcibcl, L.A. Boatucr, Phys. Rcv. Lelt. 39, 1158 (1977).

[26] T. Clicn, G. Schaack, J. Pliys. C 17, 3801, 3821 (1981).

[27] II. Braeter, W. Windsch, Ferroclectrics Lett. Sect. 10, 43 (1989).

[28] W. Windsch, II. Braeter, J. Ricdel, Solid Slale Commun. 53, 621 (1985). 